\title{
High frequency AC electric glow discharge visualization technology and application in big diameter hypersonic low-density wind tunnel
}

\author{
Wanqiu Jiang ${ }^{1,2 \dagger}$, Huacheng Qi ${ }^{2^{*}+} \mathbb{D}$, Yanguang Yang ${ }^{3}$, Yilei Shi ${ }^{2}$, Jie Wang ${ }^{2}$, Jie Li ${ }^{2}$, Zhengyi Long ${ }^{2}$ and \\ Chunman $\mathrm{Mao}^{2}$
}

\author{
* Correspondence: qiuhuacheng@ \\ cardc.cn \\ 'Wanqiu Jiang and Huacheng Qiu \\ are Co-first authors, contributed \\ equally to this work. \\ ${ }^{2}$ Hypervelocity Aerodynamics \\ Institute, China Aerodynamics \\ Research and Development Center, \\ Mianyang 621000, China \\ Full list of author information is \\ available at the end of the article
}

\begin{abstract}
In order to visualize the rarefied flow field in a $\$ 1 \mathrm{~m}$ hypersonic low-density wind tunnel, an electric glow discharge technique based on high frequency excited power has been developed. Firstly, finite element simulation analysis has been carried out, and it is concluded that the breakdown voltage can be reduced by using high frequency power supply; then an electric glow discharge apparatus has been fabricated, and the discharge images were compared with simulations; besides, a clear flow field around HB-1 standard model has been observed using this technology; finally, the influence of glow discharge on the flow field, as well as the differences between direct current and high frequency electric glow discharges is discussed at the end of this paper.
\end{abstract}

Keywords: Electric glow discharge, Flow visualization, Hypersonic low-density wind tunnel

\section{Introduction}

Flow visualization has a major influence on fluid mechanics. Several reviews and classifications of flow visualization techniques in fluid mechanics can be found in [1-3]. In hypersonic rarefied flows, due to low density and high speed of the gas flow, traditional flow visualization technologies are no longer applicable. For example, the optical visualization methods, such as shadowgraph, schlieren and interferometric methods, which make use of the refractive behavior of the gas flow to be studied exhibit a certain sensitivity limit if the average level of the gas density becomes too low [4]. Methods using tracking particles, like particle image velocimetry [5] and planar laser scattering [6], suffer from the fact that the momentum transfer between the flow and the tracer is not sufficient, so that tracking particles cannot accelerate enough and are not representative of the flow velocity.

It is in this range of rarefied gas flows that a visualization of the flow can be achieved by making use of the radiative characteristics of some gases. By means of an

(c) The Author(s). 2021 Open Access This article is licensed under a Creative Commons Attribution 4.0 International License, which permits use, sharing, adaptation, distribution and reproduction in any medium or format, as long as you give appropriate credit to the original author(s) and the source, provide a link to the Creative Commons licence, and indicate if changes were made. The images or other third party material in this article are included in the article's Creative Commons licence, unless indicated otherwise in a credit line to the material. If material is not included in the article's Creative Commons licence and your intended use is not permitted by statutory regulation or exceeds the permitted use, you will need to obtain permission directly from the copyright holder. To view a copy of this licence, visit http://creativecommons.org/licenses/by/4.0/. 
appropriate energy injection, the molecules of the flowing gas are excited to emit a characteristic radiation. Two different methods, named as electron beam fluorescence [7] and electric glow discharge [8], are most often used to add external energy into the flow. The intensity of the emitted radiation increases with the value of the local gas density, so that it becomes possible to discriminate between flow regimes of different gas density. Compared to the electron beam fluorescence setup, the electric glow discharge visualization appears to be a much simpler technique [9].

The electric discharge in gases at low pressures is accompanied by the emission of light. Since the intensity of this radiation depends on the density of the gas in the control volume, one may adapt this method to the visualization of rarefied gas flow. Free electrons and ions, which are in the test volume, are accelerated by the external electric field and can produce a cascade of secondary electrons and ions due to collisions with neutral gas molecules. In a certain density range, the emitted light intensity increases with the number of exciting collisions, and therefore, with the level of the gas density.

Two kinds of glow discharge apparatus can be applied, to visualize the flow field in a low-density wind tunnel. One uses two electrodes served as anode and cathode separately (refer to Fig. 1a), while the other uses the test model as an electrode (normally anode) and the cathode electrode(s) was (were) installed near the wind tunnel wall (Fig. 1b). The desired portion of the flow field can be covered by a suitable choice of the geometry of the electrodes, and the light radiations of the flow gas can be observed or photographed.

Since the middle of the twentieth century, electric glow discharge technology has been applied to observe hypersonic rarefied flow field structures. At present, it has become one of the necessary experimental techniques in the hypersonic low-density wind tunnels, which can realize the visualization of shock wave structure or boundary layer [10-21]. Taking the work of Yang et al. of China Aerodynamics Research and Development Center [21] as an example, the electric glow discharge technology was applied in a $\Phi 0.3 \mathrm{~m}$ hypersonic low-density wind tunnel, and the flow visualization photos provided intuitive flow images around hypersonic vehicles from $60 \mathrm{~km}$ to $100 \mathrm{~km}$ altitude.

The electric glow discharge technology has been widely applied in small diameter (< $0.38 \mathrm{~m}$ ) hypersonic low-density wind tunnels (as summarized in Table 1), however, for tunnels with bigger diameter (e.g. $>1 \mathrm{~m}$ ), there is no successful application case yet as far as in published reports. The major difficulty may be that the discharge area is much magnified with the flow diameter, and electric glow becomes unstable and is easy to

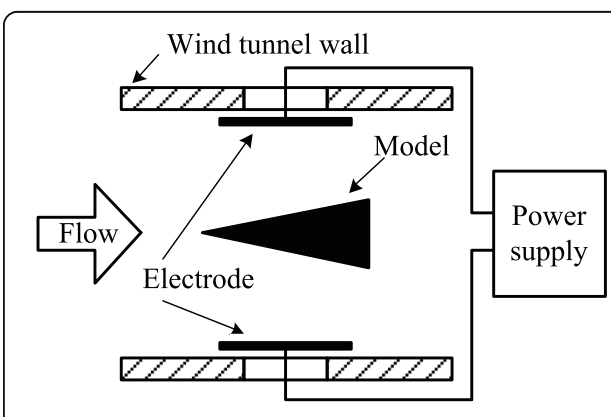

(a)

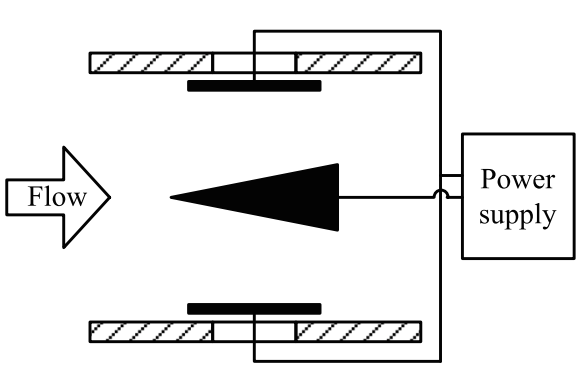

(b)

Fig. 1 Schematic of electric glow discharge apparatus applied to a hypersonic low-density wind tunnel 
Table 1 Review of electric glow discharge applications in rarefied flows

\begin{tabular}{|c|c|c|}
\hline Country & Institute / Wind tunnel / Nozzle exit diameter & Visualization Photo \\
\hline \multirow[t]{3}{*}{ Russia } & Central Research Institute of Machine Building [10] & \\
\hline & U-16 Low Density Wind Tunnel & \\
\hline & $0.25 \mathrm{~m}$ (Core diameter) & \\
\hline \multirow[t]{6}{*}{ USA } & Ames Research Center [11] & \\
\hline & Ames 3.5-Foot Hypersonic Wind Tunnel & \\
\hline & $9 \mathrm{~mm}$ & \\
\hline & The Ohio State University [12] & \\
\hline & $1.5 \mathrm{~cm}$ radius Prex tube & \\
\hline & $1.5 \mathrm{~cm}$ & \\
\hline \multirow[t]{6}{*}{ Japan } & Fukuyama University $[13,14]$ & \\
\hline & Ma10 Hypersonic gun tunnel & \\
\hline & $\sim 0.2 \mathrm{~m}$ & \\
\hline & National Defense Academy $[15,16]$ & \\
\hline & NDA Hypersonic gun tunnel & \\
\hline & $0.18 \mathrm{~m}$ & \\
\hline \multirow[t]{3}{*}{ India } & Indian Institute of Science $[17,18]$ & \\
\hline & HST1/2 hypersonic shock tunnel & \\
\hline & $0.3 \mathrm{~m}$ & \\
\hline \multirow[t]{3}{*}{ France } & The French National Center for Scientific Research [19] & \\
\hline & Hypersonic rarefied adjustable Mach Wind tunnel & \\
\hline & $0.255 \mathrm{~m}$ & \\
\hline \multirow[t]{6}{*}{ China } & China Academy of Aerospace Aerodynamics [20] & \\
\hline & FD-20 impulse tunnel & \\
\hline & $0.38 \mathrm{~m}$ & \\
\hline & China Aerodynamics Research and Development Center [21] & \\
\hline & Ф0.3 m Hypersonic Low Density Wind Tunnel & \\
\hline & $0.3 \mathrm{~m}$ & \\
\hline
\end{tabular}


cross talk with surrounding metal structures such as wind tunnel nozzle, resulting in undesired arc discharge.

In order to visualize the rarefied flow field in a $\Phi 1 \mathrm{~m}$ hypersonic low-density wind tunnel, an electric glow discharge technique based on high frequency excited power has been developed in this paper. A clear flow field around HB-1 standard model can be observed using this technology, under flow conditions of freestream flow Mach number 12, total pressure of $2 \mathrm{MPa}$ and static pressure of ca. $20 \mathrm{~Pa}$. Besides, the influence of glow discharge on the flow field, as well as the differences between low frequency/direct current (DC) and high frequency alternative current (AC) electric glow discharges, is also discussed in this paper.

\section{Experimental setup and working principle}

In order to realize flow visualization in the $\Phi 1 \mathrm{~m}$ hypersonic low-density wind tunnel, the technology in this work uses high frequency power supply to stimulate glow discharge in rarefied flow. The discharge apparatus mainly includes a power supply with $40 \mathrm{kHz}$ frequency and $0-10 \mathrm{~kW}$ power, and a pair of discharge electrodes located in the test section. As shown in Fig. 2, the power supply includes a switch control unit, a high frequency power supply unit, an impedance matching unit, as well as a remote control unit. Among them, the high frequency power supply unit is connected to a $380 \mathrm{~V}$ power grid through the switch control unit, which is mainly used to disconnect the high frequency power supply unit from the power grid in time of overcurrent and other emergencies.

The output current of the power supply is measured using a current probe. Fig. 3 presents the results for $3 \mathrm{~kW}$ of power absorbed by the glow plasma under environmental pressure of $6 \mathrm{~Pa}$. The amplitude of the applied power is found to be approximately $0.9 \mathrm{~A}$, and the frequency is $40.65 \mathrm{kHz}$.

The system increases the collision frequency and ionization ability of gas molecules by $\mathrm{AC}$ excitation of high frequency oscillations between electrodes, thus increasing the effective breakdown distance of rarefied flow field. When the frequency of power supply is low $(50 \sim 5 \mathrm{k} \mathrm{Hz})$, the breakdown/glowing voltage of gas is basically the same as

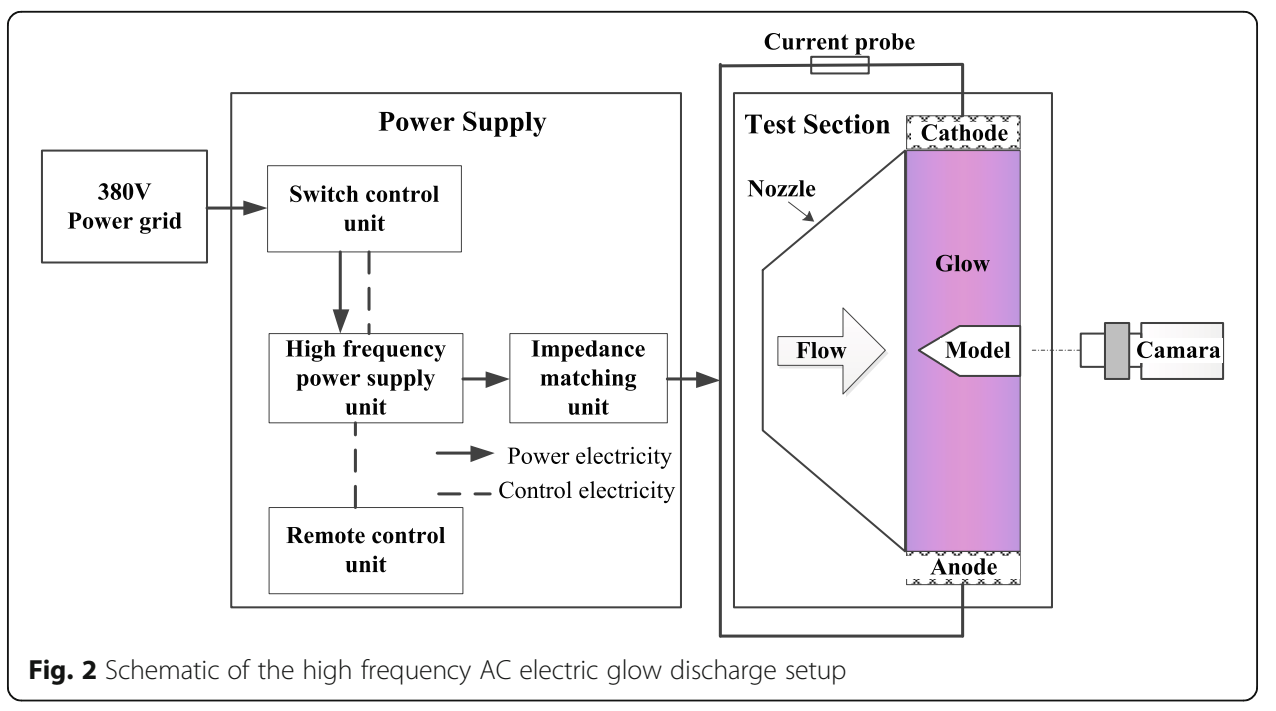




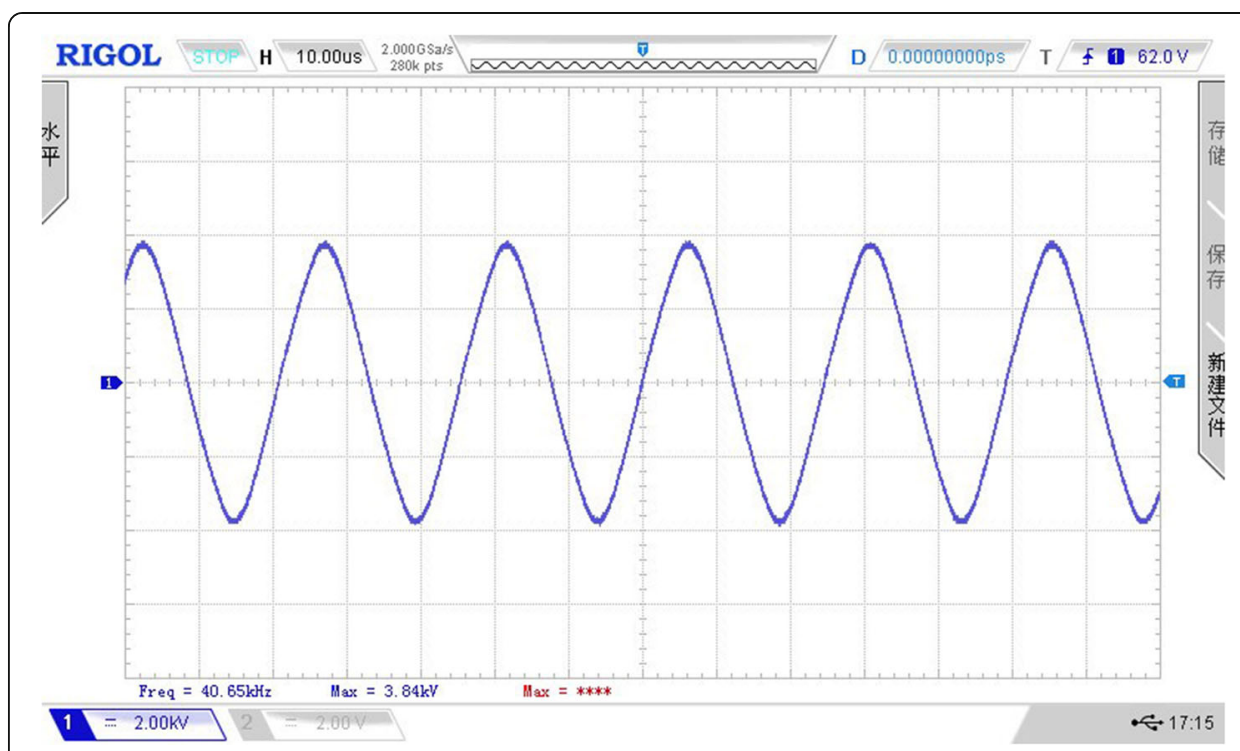

Fig. 3 Measured current of the power supply during glow discharging

that of DC discharge. While the frequency of power supply increases much higher, the breakdown/glowing voltage for electric discharge is much lower than that of DC power supply.

\section{Numerical simulation}

\subsection{Simulation model}

In this work, the glow discharge is simulated using the Plasma Module of COMSOL Multiphysics software [22], and time periodic solver is used for the periodic steadystate solution. The simulations are for a Nitrogen plasma at a pressure of $6 \mathrm{~Pa}$ by a periodic electric excitation of $40 \mathrm{kHz}$. As shown in Fig. $4 \mathrm{a}$, the model is 2D axisymmetric, and the discharge consists of two electrodes, one powered (the anode) and one

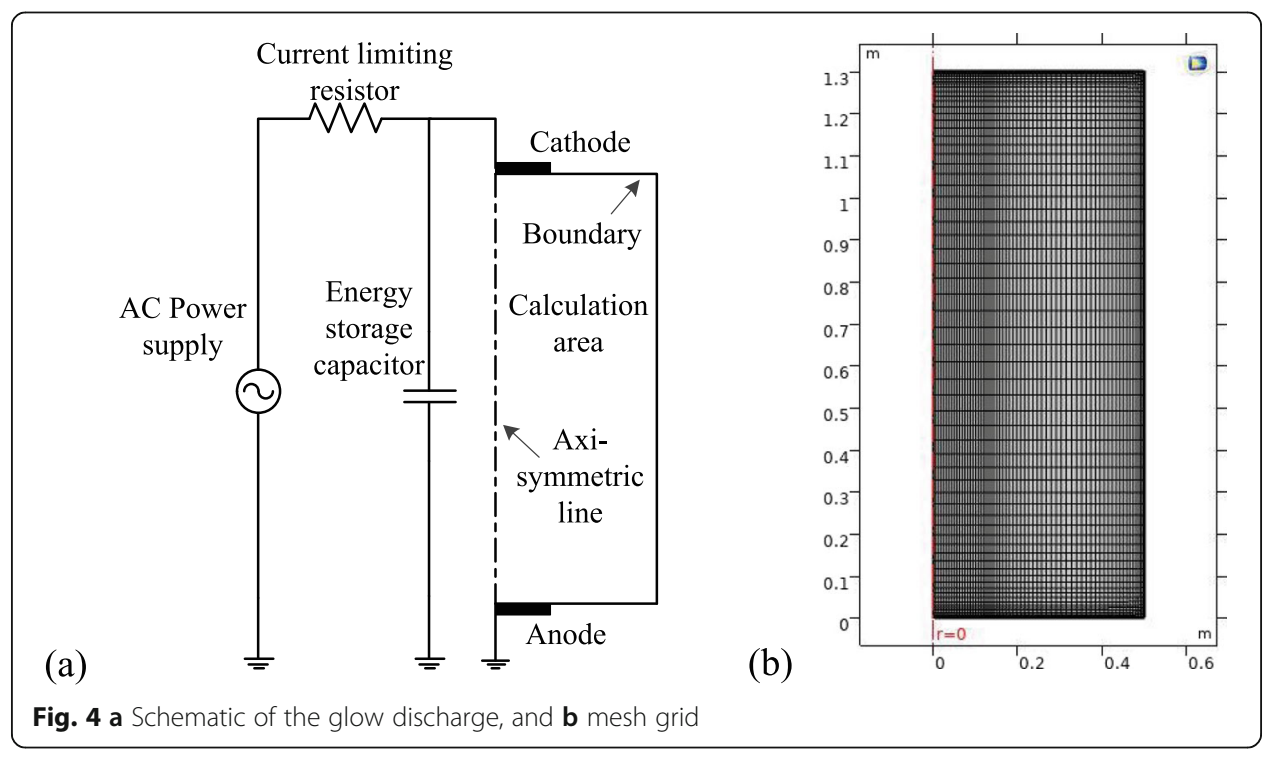


grounded (the cathode), with an electrode radius of $20 \mathrm{~cm}$ and a gap between electrodes of $1.3 \mathrm{~m}$.

The mapped mesh grid is shown in Fig. 4b. To minimize the number of degrees of freedom, the area around the electrodes, where the discharge is expected to show large gradients, is meshed with a fine mesh, while elsewhere with a coarser mesh. Besides, a boundary layer is needed to capture the separation charge between the electrons and ions close to the wall. The thickness of the first boundary layer is set at $10 \mu \mathrm{m}$, and there are ca. 5000 mapped elements in the computational area.

\subsection{Electric excitation equations}

The electron density and mean electron energy are computed by solving drift diffusion equation for the electron density. Convection of electrons due to fluid motion is neglected.

$$
\frac{\partial}{\partial t}\left(n_{e}\right)+\nabla \cdot \Gamma_{e}=R_{e}
$$

where $n_{e}$ is the electron density, $R_{e}$ is the electron source term, and $\Gamma_{e}$ is the electron flux, which defined as:

$$
\Gamma_{e}=-n_{e}\left(\mu_{e} \cdot E\right)-D_{e} \cdot \nabla n_{e}
$$

where $\mu_{e}$ is the electron mobility, $E$ is the electric field intensity, and $D_{e}$ is the electron diffusivity, which is computed as:

$$
D_{e}=\frac{k_{B} T_{e}}{m_{v} v_{m}}
$$

where $k_{B}$ is the Boltzmann constant, $T_{e}$ is the electron energy, $m_{v}$ is the electron mass, and $v_{m}$ is the electron velocity.

The electron source term $R_{e}$ in the eq. (1) is determined by the plasma chemistry using rate coefficients. Suppose that there are $M$ reactions which contribute to the growth or decay of electron density and $P$ inelastic electron-neutral collisions. In general $P \gg M$. In the case of rate coefficients, the electron source term is given by:

$$
R_{e}=\sum_{j=1}^{M} x_{j} k_{j} N_{n} n_{e}
$$

where $x_{j}$ is the mole fraction of the target species for reaction $j, k_{j}$ is the rate coefficient for reaction $j$, and $N_{n}$ is the total neutral number density.

\subsection{Boundary conditions}

An electron is emitted from the cathode surface with a specified probability when struck by an ion. These electrons are then accelerated by the strong electric field close to the cathode where they acquire enough energy to initiate ionization. Electrons are lost to the wall due to random motion within a few mean free paths of the wall and gained due to secondary emission effects, resulting in the following boundary condition for the electron flux: 


$$
-\mathbf{n} \cdot \Gamma_{e}=\left(\frac{1}{2} v_{e, t h} n_{e}\right)-\sum_{p} \gamma_{p} \cdot\left(\Gamma_{p} \cdot \mathbf{n}\right)
$$

The second term on the right-hand side of eq. (5) is the gain of electrons due to secondary emission effects, where $\gamma_{p}$ is the secondary electron yield and $\Gamma_{p}$ is the particle flux of electrons on the boundary surface. $v_{e, t h}$ is the electron thermal velocity, defined as

$$
v_{e, t h}=\sqrt{\frac{8 k_{B} T_{e}}{\pi m_{v}}}
$$

\subsection{Plasma chemistry}

The reaction process of $N_{2}$ discharge is complex, and there are many kinds of excited nitrogen molecules, so necessary simplifications should be made during the simulations. In this model, only the following particles are considered: electron $e$, nitrogen molecular $N_{2}$ and nitrogen molecular ion $N_{2}+$, which mainly comes from the direct collision ionization between $e$ and $N_{2}$, and the penning ionization between metastable states. The electronically excited states can be lumped into simplified species which results in a chemical mechanism as shown in Table 2.

\subsection{Simulation results and comparison}

In a certain low density range, the emitted light intensity increases with the number of exciting collisions, and therefore, with the level of the electron density during electric discharge process, which means the light brightness is proportional to the electron density in a certain range. Figure 5 plots the simulated electron densities in the discharged column, as well as optical images, under $6 \mathrm{~Pa}$ environmental pressure using different electric excitation power. The images, which were taken by a numerical camera mounted on a tripod, show a violet color due to the preponderant emission of the second positive system of $N_{2}$ and the presence of the ion $\mathrm{N}_{2}+$ indicating the emission of the first negative system [23]. The discharge shows the same pattern of light emission as that observed in a classical low pressure tube discharge [24], and Itoh et al. measured the spectral characteristics of the glow plasma in a hypersonic gun tunnel [25].

Both the simulations and experiments proved that, the electron density decreases in the radial direction, and this is caused by diffusive loss of electrons to the outer walls of the column where they accumulate a surface charge. Furthermore, as expected, the electron density adjacent to the electrodes is much denser when the excited power increases.

Table 2 Table of collisions and reaction modeled

\begin{tabular}{llll}
\hline Reaction & Formula & Type & $\Delta \boldsymbol{\varepsilon}(\mathbf{e V})$ \\
\hline 1 & $e+N_{2}=>e+N_{2}$ & Elastic & 0 \\
2 & $e+N_{2}=>2 e+N_{2}+$ & Ionization & 15.6 \\
3 & $e+N_{2}=>e+2 N$ & Excitation & 10 \\
4 & $e+N=>2 e+N+$ & lonization & 14.549 \\
\hline
\end{tabular}




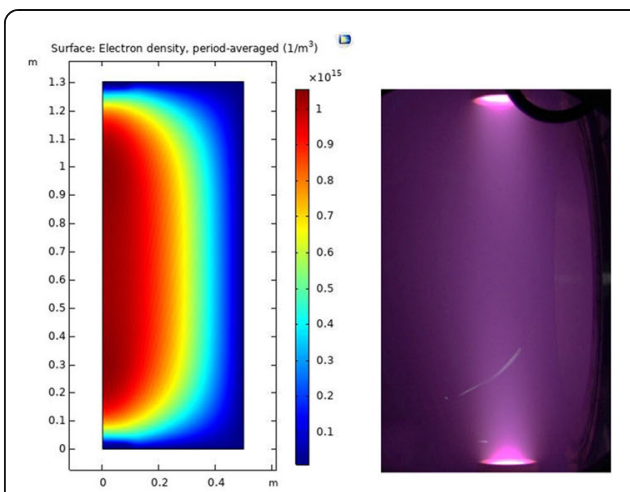

(a)

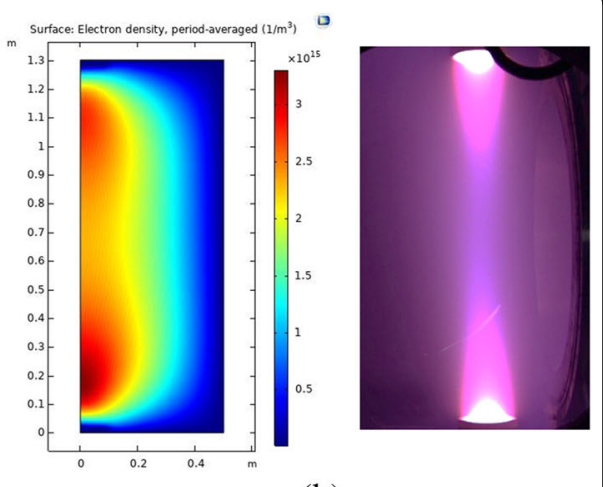

(b)

Fig. 5 Simulated electron densities and images taken by a camera under 6 Pa environmental pressure, with electric excitation power of (a) $3.0 \mathrm{~kW}$, and (b) $9.5 \mathrm{~kW}$

\section{Flow visualization result}

High frequency AC electric glow discharge, as a kind of rarefied flow field visualization technology, has been applied in the $\Phi 1 \mathrm{~m}$ hypersonic low-density wind tunnel of China Aerodynamics Research and Development Center. Figure 6 compares the glow discharge images between conditions of vacuum and HB-1 model in the test area. It can be seen that the glow around the model becomes brighter, since the electron density increases as the probability of collision between electrons near the model surface increases. Figure 7a shows the glow discharge visualization image of HB-1 standard model under the test conditions of freestream Mach number $M a 12$, total pressure $P_{0}$ of $2 \mathrm{MPa}$, static pressure $P_{\infty}$ of ca. $20 \mathrm{~Pa}$ and $0^{\circ}$ angle of attack $\alpha$, which clearly shows the flow field structure around HB-1 model. As comparison, the results of threedimensional Navier-Stokes (N-S) simulation (Fig. 7b upper) and schlieren photography (Fig. 7b lower) under the same test condition were also presented. The pressure/density contours obtained experimentally and computed numerically were found to be in good agreement.

\section{Conclusion and discussions}

In this work, a high frequency AC electric glow discharge technique has been used to provide visualizations of the flow field in a $\Phi 1 \mathrm{~m}$ hypersonic low density wind tunnel. Different from the conventional DC/low frequency glow discharge technology applied

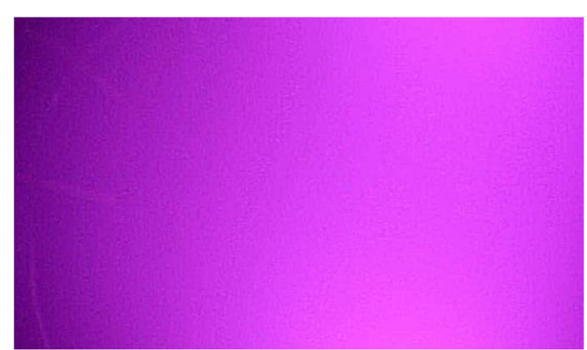

(a)

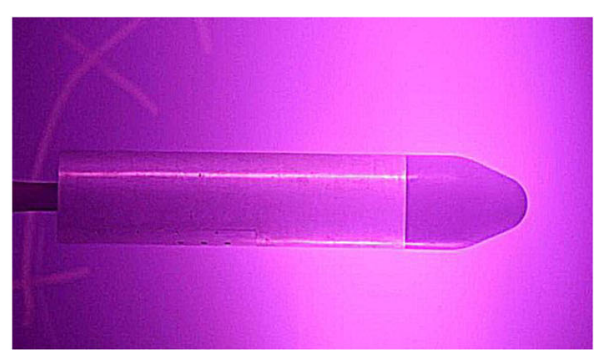

(b)

Fig. 6 Electric glow discharge images of (a) vacuum condition and (b) HB-1 model in the test area 


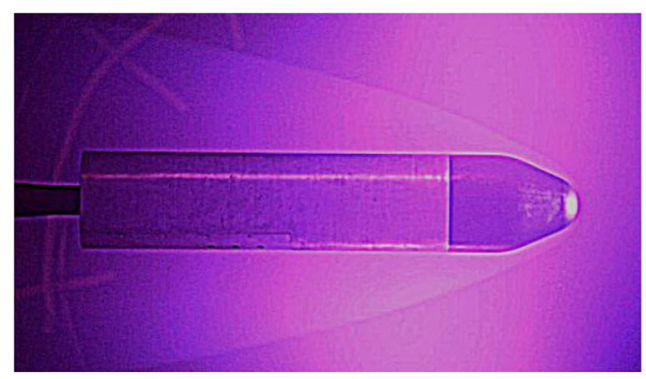

(a)

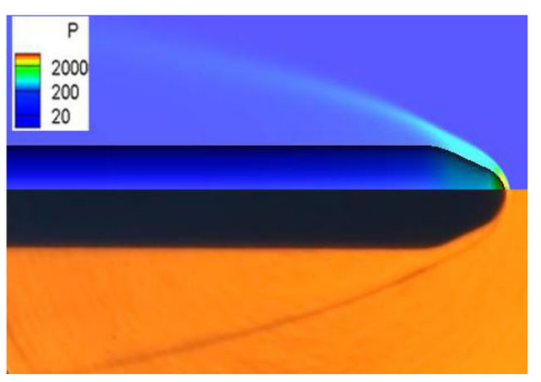

(b)

Fig. 7 Flow visualization results of $\mathrm{HB}-1$ model under flow condition: $M a=12, P_{0}=2 \mathrm{MPa}, P_{\infty} \approx 20 \mathrm{~Pa}$, using methods of (a) electric glow discharge, (b) N-S simulation and schlieren photography

in small diameter $(<0.38 \mathrm{~m})$ wind tunnels, this technology used high frequency $\mathrm{AC}$ electric power to excite glow plasma in a big flow field $(>1 \mathrm{~m})$, so that to realize the rarefied flow field visualization of big diameter wind tunnel. Pressure/density contours obtained using methods of electric discharge, N-S simulation and schlieren photography, were found to be in good agreement. In view of these results, the visualization technique by high frequency $\mathrm{AC}$ electric glow discharge is not intrusive and allows dealing with rarefied hypersonic gas flows.

In addition, the following two problems are further discussed:

\subsection{Influence of glow discharge on flow field and aerodynamic force}

Kyser etc. [26, 27] have observed that a discharge column follows the gas flow exactly when the flow velocity is constant, and adds negligible perturbance into the flow. However, when the discharge method is applied to an accelerated flow or an unsteady flow in which there exist various kinds of external forces, glow plasma cannot track gas flow because of the difference of densities of the ionized gas particle and surrounding gas. This work further verifies the influence of glow discharge on aerodynamic force in a steady flow field.

Firstly, a wind tunnel repeatability test of a spacecraft model is carried out for three times without glow discharge, and then the test is continued for one time with glow discharge on. The test results are shown in Fig. 8. For the discharge off cases, the repeatability accuracies of normal force coefficient $C_{N}$ and axial force coefficient $C_{A}$ are $0.41 \%$ and $0.45 \%$, respectively. Compared with the mean coefficients of discharge off cases, the relative deviations of $C_{N}$ and $C_{A}$ are $0.14 \%$ and $0.05 \%$ respectively when the discharge is on, which is within the error range of repeatability tests. Therefore, the influence of glow on the aerodynamic test results can be ignored for the steady flow field.

\subsection{Difference between DC and high frequency AC electric glow discharges}

In order to obtain a uniform glow plasma of the discharge column, this work uses a high frequency AC rather than a DC power. Can DC discharge also be applied to big diameter low-density wind tunnel? We try to use finite element simulations to answer this question. 


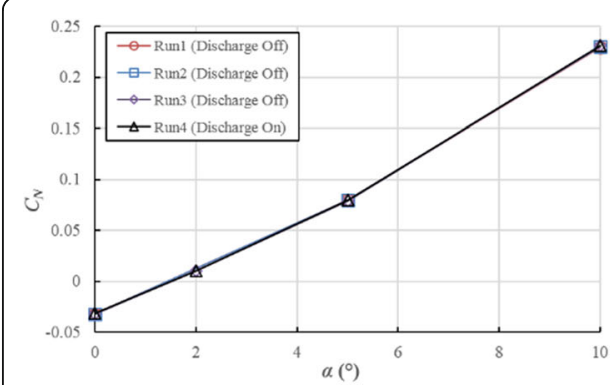

(a)

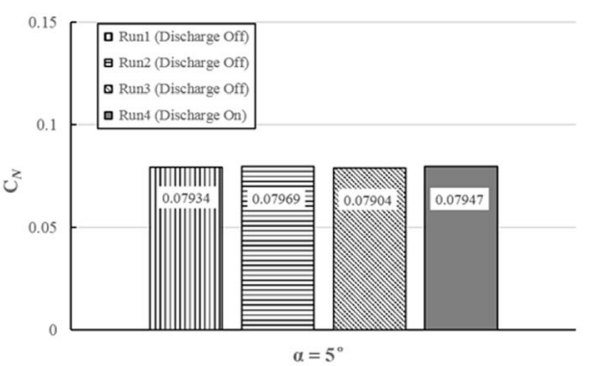

(c)

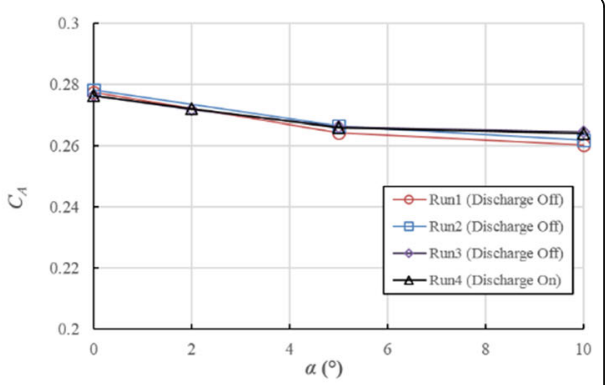

(b)

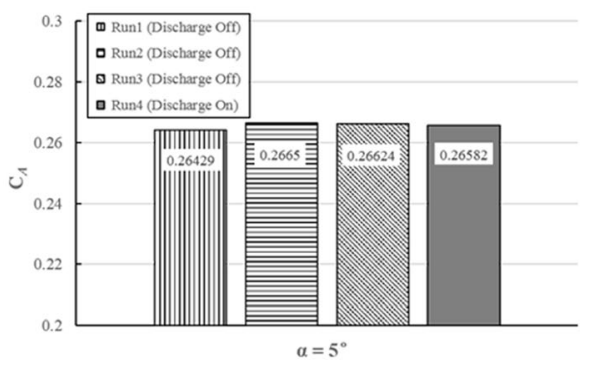

(d)

Fig. 8 Comparison of aerodynamic coefficients under the conditions of electric discharge off and on, (a) normal force coefficient $C_{N}$ (b) axial force coefficient $C_{A},(\mathbf{c}) C_{N}$ at $a=5^{\circ}$ and (d) $C_{A}$ at $a=5^{\circ}$

The simulation results of DC glow discharges are shown in Fig. 9. The electron density peaks in the region between the cathode fall and positive column. This region is sometimes referred to as Faraday dark space. The electron density also decreases rapidly in the radial direction. This is caused by diffusive loss of electrons to the outer walls of the column where they accumulate a surface charge. The build-up of negative charge leads to a positive potential in the center of the column with respect to the walls. We can note that the flow is far away from the catholic layer. Only the positive column is used to visualize the flow density.

For small diameter wind tunnel (Fig. 9a, diameter of $0.32 \mathrm{~m}$ in the case), the state of the plasma in a sufficiently long column is independent of the situation in the regions adjacent to the electrodes. However, for bigger diameter tunnel (Fig. 9b, diameter of $1.3 \mathrm{~m}$ ), DC glow discharge is difficult to completely ionize the gas between the electrodes, and the gas near the cathode is so low that almost no glow is produced, so only the glow near the anode can be used to display the flow field.

Because DC glow discharge is stimulated by stable voltage, with the increase of discharge distance, the density of glow plasma decreases and becomes unstable; moreover, it is easy to cross talk with surrounding metal structures such as wind tunnel nozzle, resulting in undesired arc discharge. While for the high frequency AC electric glow discharge, there is no electric field effect in the intermittent AC pulse discharge, and the compound dissipation of charged particles is effective to restrain arc discharge, besides, the intermittent pulse discharge can inhabit arc discharge by reducing the thermal accumulation effect. Therefore, the high frequency AC electric glow discharge technology used in this work has the advantages of self-maintaining and stable discharge, and it can stimulate more uniform glow 


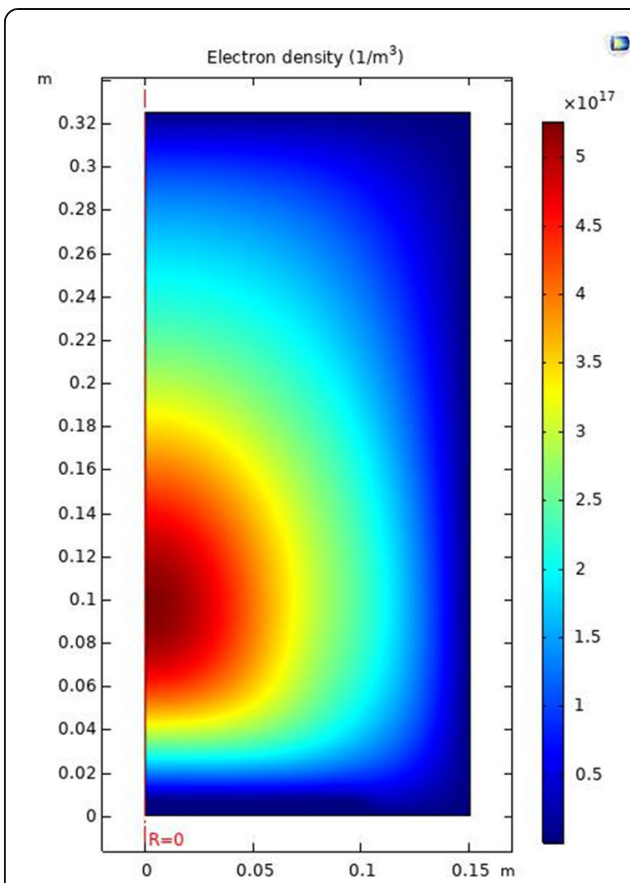

(a)

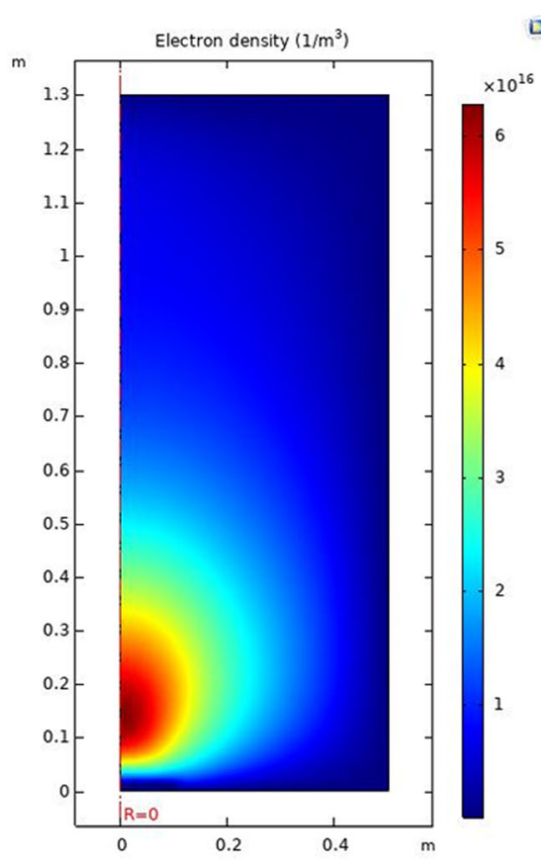

(b)

Fig. 9 Simulated electron densities under $6 \mathrm{~Pa}$ environmental pressure, with $1 \mathrm{kV} \mathrm{DC}$ excitation power for spans of (a) $0.32 \mathrm{~m}$ and (b) $1.3 \mathrm{~m}$

discharge, thus is more suitable for the flow field visualization of big diameter wind tunnels.

\section{Abbreviations}

$n_{e}$ : Electron density; $R_{e}$ : Electron source term; $\Gamma_{e}$ : Electron flux; $\mu_{e}$ : Electron mobility; E: Electric field intensity; $D_{e}$ : Electron diffusivity; $k_{B}$ : Boltzmann constant; $T_{e}$ : Electron energy; $m_{v}$ : Electron mass; $v_{m}$ : Electron velocity; $x_{i}$ : Mole fraction of the target species for reaction j; $k_{i}$ : Rate coefficient for reaction j; $N_{n}$ : Total neutral number density; Ma: Freestream Mach number; $P_{0}$ : Total pressure; $P_{\infty}$ : Static pressure; $a$ : Angle of attack; $C_{N}$ : Normal force coefficient; $C_{A}$ : Axial force coefficient

\section{Acknowledgements}

The authors gratefully thank Taijiang Ma and Hong Li for assistance in wind tunnel experiments. The authors would also like to thank Tong Li for polishing this English manuscript.

\section{Authors' contributions}

$\mathrm{HQ}$ acquired the project funding. $\mathrm{HQ}$ and WJ were major contributors in writing the manuscript. WJ, HQ, JW, JL, ZL and CM carried out experiments. YY and YS reviewed and revised the manuscript. All authors read and approved the final manuscript.

\section{Funding}

This work was financially supported by the National Natural Science Foundation of China (NSFC) (Project Nr.: 11802329).

\section{Availability of data and materials}

Not applicable.

\section{Declarations}

\section{Competing interests}

The authors declare that they have no competing interests.

\section{Author details}

${ }^{1}$ College of Aerospace Engineering, Nanjing University of Aeronautics and Astronautics, Nanjing 210016, China. ${ }^{2}$ Hypervelocity Aerodynamics Institute, China Aerodynamics Research and Development Center, Mianyang 621000, China. ${ }^{3}$ China Aerodynamics Research and Development Center, Mianyang 621000, China. 
Received: 15 March 2021 Accepted: 10 May 2021

Published online: 17 June 2021

\section{References}

1. Merzkirch W (1987) Flow visualization, 2nd edn. Academic Press, Orlando

2. Freymuth P (1993) Flow visualization in fluid mechanics. Rev Sci Instrum 64(1):1-18. https://doi.org/10.1063/1.1144433

3. Estruch D, Lawson NJ, Garry KP (2009) Application of optical measurement techniques to supersonic and hypersonic aerospace flows. J Aerosp Eng 22(4):383-395. https://doi.org/10.1061/(ASCE)0893-1321(2009)22:4(383)

4. Kunnel WB, Hurlbut FC (1957) Luminescent gas flow visualization for low density wind tunnels. J Appl Phys 28:827-835

5. Liu D, Baccarella D, Lee T (2017) Investigation of flow combustion dynamics of an ethylene transverse jet in a model scramjet. In: 55th AIAA aerospace sciences meeting, Grapevine, Texas, pp 2017-0341

6. Kong XP, Chen Z, Zhang KL, Qiu H, Yi SH (2017) Investigations on the shock train structures and unsteadiness. In: 21st AIAA international space planes and hypersonics technologies conference. Xiamen, pp 2017-2388

7. Gochberg LA (1997) Electron beam fluorescence methods in hypersonic aerodynamics. Prog Aerosp Sci 33(7-8):431-480 https://doi.org/10.1016/S0376-0421(97)00002-X

8. Howatson AM (1976) An introduction to gas discharges, 2nd edn. Pergamon Press, Oxford

9. San W, Ge Y (1982) Two methods for low density flow visualization. In: Merzkirsh W (ed) Flow visualization II. Hemisphere, Washington D. C, pp 421-425

10. Kalugin VM (1966) Ultrasensitive glow discharge method for visualizing hypersonic flows of rarefied gases. J Appl Mech Tech Phys 4:108-112

11. Horstman CC, Kussoy MI (1968) Hypersonic viscous interaction on slender cones. In: 6th AIAA aerospace sciences meeting, New York, pp 68-62

12. Adamovich IV, Rich JW (2007) Emission and shock visualization in nonequilibrium nitrogen afterglow plasma. J Appl Phys 102(8):083303. https://doi.org/10.1063/1.2798984

13. Nishio M (1993) Method for visualizing gas temperature distributions around hypersonic vehicles by using electric discharge. AIAA J 31(6):7-12

14. Nishio M, Sezaki S, Nakamura H (2004) Visualization of flow structure around a hypersonic re-entry capsule using the electrical discharge method. J Vis 7:151-158

15. Itoh H, Mizoguchi M (2016) Experiments on unsteadiness associated with cylinder-induced shock-laminar boundary layer interaction in hypersonic flow. In: 46th AlAA fluid dynamics conference, Washington D C, pp 2016-3648

16. Itoh H, Mizoguchi M (2017) Method for visualizing viscous interaction in hypersonic low-density flows using electrical discharge. J Spacecraft Rockets 54(1):225-232. https://doi.org/10.2514/1.A33479

17. Jagadeesh G, Srinivasa Rao BR, Nagashetty K, Reddy NM, Reddy KPJ (1996) A new technique for visualization of shock shapes in hypersonic shock tunnel. Curr Sci 71(2):128-130

18. Nagashetty K, Syed Saifuddin K, Saravanan S, Gurumurthy KS, Jagadeesh G, Reddy KPJ (2000) Visualization of shock shapes around blunt bodies at hypersonic Mach number in a shock tunnel using electrical discharge technique. Curr Sci 79(8):1086-1089

19. Leger L, Sellam M, Barbosa E, Depussay E (2013) Visualization by discharge illumination technique and modification by plasma actuator of rarefied Mach 2 airflow around a cylinder. Meas Sci Technol 24(6):065401. https://doi.org/10.1088/ 0957-0233/24/6/065401

20. Sha XG, Wen S, Yuan ML, Lu HB, Ji F (2018) Visualization of shock wave in hypersonic flow using electric discharge. J Experiments Fluid Mechanics 32(3):87-93 (in Chinese)

21. Yang YG, Li M, Li ZH, Li XG, Dai JW (2016) Aerodynamic force/heating measurement on hypersonic vehicle across different flow regions. Acta Aerodynamica Sinica 34(1):5-13 (in Chinese)

22. COMSOL (2020) Plasma module user's guide, version COMSOL 5.5. COMSOL Co., Ltd.

23. Lofthus A, Krupenie (1977) The spectrum of molecular nitrogen. J Phys Chem Ref Data 6(1):113-308. https://doi.org/10.1 $063 / 1.555546$

24. Hu JT, Wang JG, Liu XY, Liu DW, Lu XP, Shi JJ, Ostrikov K (2013) Effect of a floating electrode on a plasma jet. Phys Plasmas 20(8):083516. https://doi.org/10.1063/1.4817954

25. Itoh H, Tanabe H, Mizoguchi M (2019) Spectral measurements in electrical discharge glow plasma produced in hypersonic separated flow. In: AIAA Scitech 2019 Forum, San Diego, California, pp 2019-1504

26. Kyser JB (1964) Tracer-spark technique for velocity mapping of hypersonic flow fields. AlAA J 2(2):393-394. https://doi. org/10.2514/3.2309

27. Matsuo K, Setoguchi T, Yamamoto Y (1981) The error in measuring an accelerated flow velocity by a spark tracer method. Bull JSME 24(193):1168-1175. https://doi.org/10.1299/jsme1958.24.1168

\section{Publisher's Note}

